\title{
Break Through Treatment of Cerebral Palsy in the Light of Nucleopathy
}

\author{
Shahid Sheikh $\mathrm{H}^{*}$ \\ Department of Neurology, Institute of Nucleopathy, Pakistan
}

Submission: March 03, 2019; Published: March 18, 2019

*Corresponding author: Shahid Sheikh H, Department of Neurology, Institute of Nucleopathy, Pakistan

Abstract

Cerebral Palsy, a poorly understood diagnosis established in the conventional Allopathic Neurology, limited to the Cytopathy. Up until today, it provides no treatment, however intrinsic symptomatic treatments are designed by Psychiatrists, Neurologists and Neurosurgeons. Actually, in the Nucleopathy view of Sheikh's Syndrome, It is defined as Multifocal Sub Nucleus Neuronitis (MFSNN). The chronicity of this disease starts from the early developmental age in the uterine.

Mother or father's chromosomes carry the Neuro invasive viral genomes, therefore, at the time of fertilization, the viral genomes survive and flourish. First trimester, the construction of the Neuro Disk, The brain and the spinal cord development take place. Through the mitotic environment in the uterine equally favors the genomic proliferation and its distribution in the variety of developing Neurons sporadically. The overwhelming viral genomic proliferation at the outset, may cease the fetal development and cause a miscarriage. If fetus survives this neopathogenesis, a number of nuclei of the infected Neurons left behind as a potential focus, where the participating neuronal homeostasis will be compromised under its influence.

The seed of the future ailments sown. This is the onset of unexplainable "pain" and at the outset the "Disability". Mother's immunity always faces this challenge to rectify this neopathogenesis. Preamble of infant's late miles stone, mental retardation, physical incapacitation/disabilities originate here. The mother \& the Child health has always been a global challenge without the knowledge of Sheikh's Syndrome MFSNN [5].

Currently, the genes editing phenomenon during pregnancy has not substantiated a possibility to remove the viral proliferating genomes during pregnancy. The best caution against C.P. and many other off shoots of neuroviral induced problems in fetus are the pre-pregnancy screening of antibodies accumulation against these Neuro invasive viral genome. Any number of the antibodies IgG or IgM over the normal limits are a clear indication of high risk pregnancy and or complete male or female infertility.

C.P. exists almost in every community across the planet with no cure. Patients suffering from this ailment live a very disturbed and painful quality of life. Prominent derogatory health conditions prevail swiftly that carry a social and financial burden on the family. Conventional allopathy has no solution but the symptomatic transitory relief. Interestingly, many physicians cater the remedial cocktail to C.P. patients. Therefore, to decrease the frequency and inconvenience of the symptomatology, it is very logical to start tracing the involvement of the nervous system right from the effected tissues involved in this ailment and track the possible neopathogenesis of C.P.

The pathophysiology of the controlling neurons are never taken into an account for a possible involvement in the system's malfunctioning. Long behold, as we tracked this novel phenomenon and found a new revelation.5 The controlling neurons nuclei overwhelmed with the Neuroinvasive viral genomic proliferation, at the time of intra-uterine development, possibly in the first trimester of the pregnancy incapacitating the fetal neuronal homeostasis and/ or development.

Keywords: Immunity; Pathogens; Organs; Homeostasis; Tissues; Frontier; Neopathogenesis

Abbreviations: AFM: Atomic Force Microscopy; MFSNN: Multifocal Sub Nucleus Neuronitis

\section{Introduction}

Conventionally, allopathy has designed the understanding of human body's configuration and its ailments through the systems that composed of multiple organs that the organs are composed of tissues \& membranes and cells. Allopathy has considered the cell being the last frontier, where Neopathogenesis begins and resident immunity swiftly responds with the antibodies to defy the pathogens to establish the homeostasis. We call it "CytoPathy".
Clinicians engage in a variety of diagnostic tools to evidence such Cyto-pathology to confirm their diagnoses and tailor a medical or surgical plan according to the given established protocols. Conventionally, micro the million times magnification, limited the scientific understanding of the neopathogenesis, whereas, the one Billion times magnification by the Atomic Force Microscopy (AFM) has brought a new paradigm in the view. It expanded our understanding of the emerging neopathogenesis 
\& pathophysiology of a given symptomatic onset seen rooted in the nucleus of a given controlling Neuron. This has established a new dimension of neopathogenesis; called Nucleopathy [1].

Now there is an urgent need to recognize the Nucleopathy as a separate discipline. No more we can logically treat a disease based on the symptomatic realm of outdated guidelines, adhering to "Etiology Unknown".

Today, majority of the ailments have only symptomatic relief/ "treatment"?

There is an urgency to take a deeper look at the source of ailments and try to define the possible etiology for a better, comprehensive and a permanent relief to the ailing humanity. Nucleus of a given cell being the controlling entity for that cell's homeostasis, its timely development and its functions. So is true of the controlling Neurons of the Brain. In 2004, Late Dr. Edward Wagoner and his team at the University of California at Irvine did not fathom the idea that they were about to change a paradigm of etiology [2].

His team Dr. Alex Malkin, Dr. Alex McPhearson and Dr. Marco Plomp used the AFM and revealed the real time "NanoPathological" series of events that Dr. Wagoner reported in his last publication[3]. I was fortunate to have this opportunity to evaluate their findings clinically and integrate into the clinical practice to best diagnose and help alleviate the symptoms and neopathogenesis, that help prevail the homeostasis of cells, tissues, organs, system that promote the quality of life[4].

Cyto-pathology is no longer an absolute reliable tool to finalize the proper diagnoses. Currently, so called treatments are merely a symptomatic pacification to borrow time for the resident immune system to recongregate/ revitalize against the pathogens in question. The Nucleo-pathology of the controlling neurons indeed is the paradigm shift, the grass root Instigator of the basic symptomatology that results into the disruption of the normal homeostasis [4]. However, pacifying the symptoms is not the final treatment of the chronic ailment. On the contrary it is the opportunity given to the pathophysiology to continue to grow into a bigger challenge, eventually becoming an incurable disease, leading to Disability.

To date, this phenomenon has been a hidden secret of nature. Now that is opened, it is unraveling the possible etiologies of the unknown nature of the conventional diseases. The "Sheikh's Syndrome", is rightfully a very well established guideline to see any disease's root cause etiology and possible treatment to eradicate the ailment [5].

\section{Material \& Methods}

Patients with age ranging from pnception onward suffering from a variety of neurological deficits, tested for the increase serum antibodies IgG \& IgM against proliferating Neuro-invasive viral genomes, Sub-Nucleusly. All patients were found positive multi folds for Herpes Simplex Virusand Cytomegalo Virus. This substantiated the overwhelming viral genomic burden in the nuclei of the controlling neurons that had disrupted the normal function. Patients were given the selected antiviral infusion therapy with the supportive medicine to establish the mainstay of the treatment twice a day for 15 days.

Infusions consisted of Dextrose 5\% $500 \mathrm{ml}$ with selected antiviral, Dexamethasone $1 \mathrm{ml}$, Vitamin B12, Ranitidine $2 \mathrm{ml}$ s.o.s and Antihistamine 2ml. Gravitate/ Maxolon sos were used on a standby basis to retard the possibilities of nausea and vomiting. All patients responded well to the antiviral infusion therapy relieving the C.P. symptomatology after 1st five days of the treatment. Minor headaches and sporadic and transient body pains were reported that were rectified with additional use of analgesics.

\section{Results}

Patients well tolerated the antiviral infusion therapy without any remarkable event. All patients reported increasingly improving the homeostasis, specially, on the 5th day of the antiviral infusion therapy.

\section{Conclusion}

Once the sub-nuclei CMV genomic proliferation deteriorated via its appropriate antiviral infusion therapy, the nuclei regained their control over their respective cell body to reinstitute homeostasis. This substantiated the actual cure of this disease. A wonderful step to return the quality of life to the mankind.

\section{Acknowledgement}

Our organization is grateful for their commitment dedication and empathy for the patient care and providing personal support to patient, treatment protocols in achieving prognoses positive.

1. Dr. Khalid Hussain Rajper, MBBS

2. Dr. Uroosa Awan, MBBS

3. Mrs. Surriya Sarfraz, RN.

4. Ms. Zamiha Abdul Wahid, RN

\section{References}

1. Shahid Hussain Sheikh (2018) Nucleopathy, The New Dimension of The Allopathy. Biomed J Sci \&Tech Res 4(4).

2. Wagner EK, Webster RG, Granoff A (1999) Herpes Simplex Virus--Molecular Biology. In: Encyclopedia of Virology, ( $2^{\text {nd }}$ edn.), Academic Press, pp. 686-697.

3. Wagner EK, Garcia Ramirez JJ, Stingley SW, Aguilar JS, Buehler L, et al. (2002) Practical Approaches To Long Oligonucleotide-Based DNA Microarray: Lessons From Herpes Viruses. Prog Nucleic Acid Res Mol Biol 71: 445-492.

4. (2012) The Sheikh's Syndrome. IOSR Journal of Dental and Medical Sciences 1(5).

5. (2014) Neuro Invasive Viruses the Silent \& Slow Killers. IOSR Journal of Dental and Medical Sciences 13(3). 

(C) Commons Attribution 4.0 License

DOI: 10.19080/GJIDD.2019.06.555689
Your next submission with Juniper Publishers will reach you the below assets

- Quality Editorial service

- Swift Peer Review

- Reprints availability

- E-prints Service

- Manuscript Podcast for convenient understanding

- Global attainment for your research

- Manuscript accessibility in different formats

( Pdf, E-pub, Full Text, Audio)

- Unceasing customer service

Track the below URL for one-step submission https://juniperpublishers.com/online-submission.php 